\title{
The Structure of a Langmuir Monolayer of Methyl Eicosanoate as Determined by X\#Ray Diffraction and Brewster Angle Microscopy
}

\section{Citation}

Foster, W. J., M. C. Shih, and Peter S. Pershan. 1996. The structure of a Langmuir monolayer of methyl eicosanoate as determined by x\#ray diffraction and Brewster angle microscopy. Journal of Chemical Physics 105(8): 3307-3315.

\section{Published Version}

doi:10.1063/1.472185

\section{Permanent link}

http://nrs.harvard.edu/urn-3:HUL.InstRepos:10357478

\section{Terms of Use}

This article was downloaded from Harvard University's DASH repository, and is made available under the terms and conditions applicable to Other Posted Material, as set forth at http:// nrs.harvard.edu/urn-3:HUL.InstRepos:dash.current.terms-of-use\#LAA

\section{Share Your Story}

The Harvard community has made this article openly available.

Please share how this access benefits you. Submit a story.

\section{Accessibility}




\title{
The structure of a Langmuir monolayer of methyl eicosanoate as determined by $\mathrm{x}$-ray diffraction and Brewster angle microscopy
}

\author{
W. J. Foster, ${ }^{\text {a) }}$ M. C. Shih, ${ }^{\text {b) }}$ and P. S. Pershan \\ Department of Physics and Division of Applied Sciences, Harvard University, Cambridge, \\ Massachusetts 02138
}

(Received 13 February 1996; accepted 14 May 1996)

\begin{abstract}
Relaxed Langmuir monolayers of methyl eicosanoate were studied using Brewster angle microscopy (BAM) and grazing incidence $\mathrm{x}$-ray diffraction (GIXD). The structure of the various phases in this system was determined and compared to previous isotherm and microscopy measurements. At low pressure and low temperature, a crystalline phase with tilt toward nearest neighbor, $I\left(L_{2}^{\prime \prime}\right)$, is observed. At a temperature of $\sim 14{ }^{\circ} \mathrm{C}$ and low pressure there is a transition to a phase with tilt toward next-nearest neighbor, $F\left(L_{2}^{\prime}\right)$. Finally, as the temperature continues to be raised at low pressure, there is a transition to a phase where the two $F\left(L_{2}^{\prime}\right)$ peaks have the same values of $Q_{x y}$, here called the $\tau$ phase, with a Rotator IV-like structure. At high pressure and low temperature, an untilted, orthorhombic phase, $U^{\prime}(C S)$, is observed. As the temperature is increased, a second untilted, orthorhombic phase, $U(S)$, is observed, beginning at $\sim 12^{\circ} \mathrm{C}$. Above $21^{\circ} \mathrm{C}$ and at high pressure, a Rotator-II-like phase is seen, with an undistorted, untilted structure. Finally, results from BAM measurements are used to monitor the texture of the film in the different phases.

(C) 1996 American Institute of Physics. [S0021-9606(96)00932-4]
\end{abstract}

\section{INTRODUCTION}

One of the fundamental problems in condensed matter physics is understanding the relationship between the microscopic structure of a constituent molecule and the properties and structure of a macroscopic quantity of material. Although significant progress has been made in studies of solids composed of individual atoms, such as semiconductors and metals, ${ }^{1}$ the problem is significantly more complicated for organic materials formed from larger, more complex molecules. ${ }^{2,3}$ The latter represents a particularly challenging area since numerous possible effects such as Van der Waals, electrostatic, and hydrophobic interactions, as well as conformational isomorphisms of the relatively large molecules, make the problems complicated. ${ }^{4}$ One subject of continuing interest in the field of organic materials is that of Langmuir monolayers (LMs). ${ }^{5-8}$

There is now a vast literature, with a strong tradition, on the physical properties of LMs dating back to Langmuir's initial work over eighty years ago. ${ }^{9}$ However, more recent theoretical work by Nelson and Halperin ${ }^{10}$ on the statistical physics of melting in two dimensions stimulated interest in these systems from a new perspective. The field is continuing to develop and Kaganer et al. have recently attempted to explain the phase sequence in simple LM systems in terms of a mean field theory. ${ }^{8,11}$ Experimental progress, on the other hand, had been relatively slow until recently. The advent of synchrotron $\mathrm{x}$-ray sources and the development of fluorescence and Brewster angle microscopy (BAM), provided the

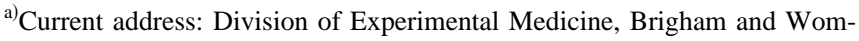
en's Hospital and Department of Medicine, Harvard Medical School, 221 Longwood Avenue, Boston, Massachusetts 02115.

${ }^{b}$ Current address: Department of Physics, National Chung-Hsin University, Tai-Chung, Taiwan.
}

ability to gather microscopic structural information, as well as to directly image the domain texture of these films. ${ }^{6,12-20}$

The development of synchrotron based grazing incidence $x$-ray diffraction (GIXD) techniques for measuring the microscopic structure (i.e., lattice parameters and molecular tilt) of the LM phases with long range order is considered by some to be an important recent developments in condensed matter physics. ${ }^{21-23}$ An important advantage this technique brings to the thermodynamics of LMs is that from a measure of the angular position of the Bragg peaks of the twodimensional LM lattice, it is possible to obtain the size and shape of the microscopic unit cell. The area per molecule determined in this way is an intrinsic microscopic variable that does not depend on assumptions that must be used to extract the molecular area from macroscopic isotherm measurements. A surprising result of an earlier study ${ }^{24}$ of behenic acid $\left[\mathrm{CH}_{3}\left(\mathrm{CH}_{2}\right)_{20} \mathrm{COOH}\right]$ at $T \sim 20^{\circ} \mathrm{C}$ found that for certain regions of the isotherm, the microscopic area/ molecule determined by GIXD, $A_{X}$, did not scale with the macroscopically determined trough area, $A_{T}$. Furthermore, it was found that in certain parts of the isotherm, the dynamics by which $A_{X}$ achieved a steady state were extremely slow, sometimes of the order of several hours. To do these studies, Schlossman et al. developed ${ }^{17,25}$ a technique for measuring what is called a relaxation isotherm (RI); this will be described below. The work in this paper combines BAM measurements with $\mathrm{x}$-ray scattering measurements on a Langmuir monolayer.

The structure and kinetics of LMs are determined by a delicate balance between chain-chain interactions and head group interactions. One unfortunate aspect of the fatty acids as a system to study is the tendency of the polar headgroups to form hydrogen bonded networks that might inhibit the achievement of true equilibrium. In order to try to get around 
this problem, the present series of measurements was conducted on methyl eicosanoate $\left[\mathrm{CH}_{3}\left(\mathrm{CH}_{2}\right)_{18} \mathrm{COOCH}_{3}\right]$, the methyl ester of the saturated fatty acid, eicosanoic acid. Replacement of the proton on the acid group with the methyl group reduces hydrogen bonding between molecules. Earlier relevant studies of Langmuir monolayers of esters are those of E. Stenhagen ${ }^{26}$ and M. Lundquist. ${ }^{27}$

\section{EXPERIMENT}

Measurements of surface pressure $(\pi)$ area isotherms on LM systems are usually conducted by compressing the film at a fixed rate..$^{8,23,26,28-30}$ Unfortunately, there are situations when the LM exhibits long relaxation times and, unless the compression rate is uncommonly slow, it is unlikely that the measured isotherm will correspond to thermal equilibrium. ${ }^{24,25,31-34}$ To circumvent this problem, isotherms are performed, in this study, using the relaxation technique, ${ }^{24,25,35}$ in which $\pi$ is allowed to relax between small sequential compressions of the macroscopic area per molecule, $A_{T}$. Typical compression steps are $1 / 4 \AA^{2} / \mathrm{mol}$. The relaxation time between compressions is determined by monitoring $\pi$ as a function of time following each incremental compression. The next incremental compression is not made until five measurements are within some predetermined small value, $\epsilon$, of each other. The $\epsilon$ and time between measurements are selected to insure that the film is relaxed (typically, time $=60 \mathrm{sec}$ and $\epsilon=0.015 \mathrm{dynes} / \mathrm{cm}$ ). Only after $\pi$ has relaxed is the film again compressed. This cycle of compressing and monitoring is continued throughout the entire isotherm.

The BAM, ${ }^{13}$ used in these measurements, was custom made. It consists of a double walled cell that is sealed using o-rings. An Omnichrome argon-ion laser was used to illuminate the sample at a typical power of $100 \mathrm{~mW}(\lambda=488 \mathrm{~nm})$. Convection caused by laser heating of the trough was avoided by building a recess in the bottom of the trough into which the laser heat could be dissipated. The recess was then filled with a quartz spacer to insulate the water in the trough from the optical absorber.

The apparatus used to conduct the x-ray diffraction measurements has been described previously. ${ }^{25,35}$ It consists of the Harvard-Brookhaven liquid surface spectrometer on beamline x22b at Brookhaven's National Synchrotron Light Source and a Braun Position-Sensitive Detector. The inplane resolution is defined by a $2 \times 10^{-3}$ mradian Soller slit, yielding an in-plane resolution of $\Delta Q_{x y}=0.005 \AA^{-1}$ at a wavelength of $1.55 \AA$. The flux incident on the sample was typically $10^{9}$ photons $/ \mathrm{cm}^{2} / \mathrm{sec}$.

In this paper, a double notation is used to describe the LM phases: The first notation is based on that used to describe the symmetry of the ordered liquid crystal phases $^{17,20,25,36}$ and will be easier to interpret, at least for some readers, than the second notation that is more traditional to the field ${ }^{37}$ Structures observed here that have been observed previously in Langmuir monolayers include the $F\left(L_{2}^{\prime}\right)$ phase, in which the alkane chains are tilted towards their next nearest neighbor and the $I\left(L_{2}^{\prime \prime}\right)$ phase, where the

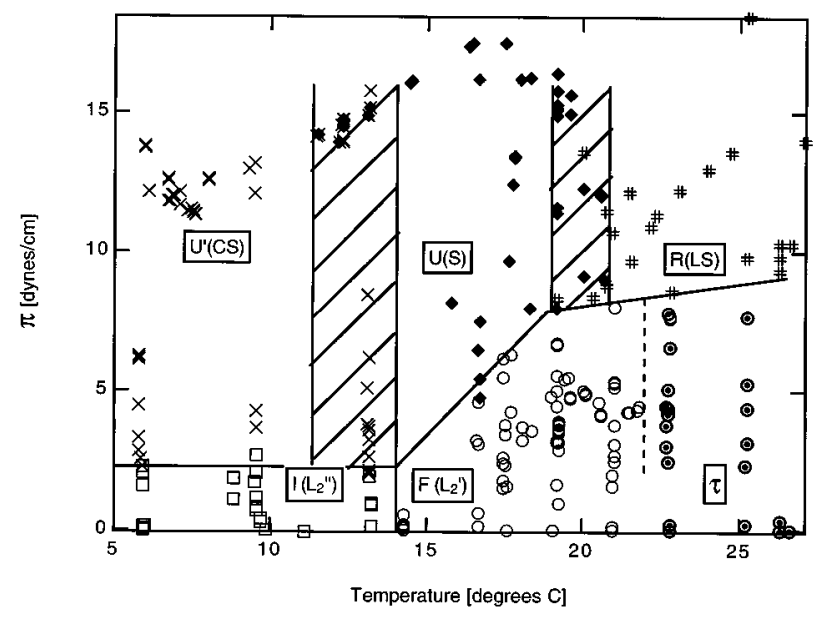

FIG. 1. $\pi-T$ phase diagram of a Methyl Eicosanoate. The phases are represented as follows: $\square-I\left(L_{2}^{\prime \prime}\right), \bigcirc-F\left(L_{2}^{\prime}\right), \odot-\tau, \times-U^{\prime}(C S), \diamond U(S)$, $\#-R(L S)$. The solid lines represent phase boundaries. In the case of the $U^{\prime}(C S)-U(S)-R(L S)$ transitions, the shaded regions represent observed limits of coexistence due to supercooling or superheating.

alkane chains are tilted toward the nearest neighbor. Untilted phases include the $U(S)$ phase, a distorted hexagonal, the $U^{\prime}(C S)$, also a distorted hexagonal but with a larger lattice, and the $R(L S)$, which possesses a rotator II structure.

\section{X-RAY DIFFRACTION}

The points shown on the $\pi-T$ phase diagram illustrated in Fig. 1 represent a summary of the observations made on a methyl eicosanoate LM.

There are six observed phases, of which three have no measurable tilt of the alkane chains. These same three untilted phases are seen in many long-chained surfactant systems. ${ }^{16,38,39}$ The phases labeled $U^{\prime}(C S)$ and $U(S)$ possess untilted, orthorhombic structures that differ primarily in the area of the unit cell. $R(L S)$ is a Rotator-II-like phase in

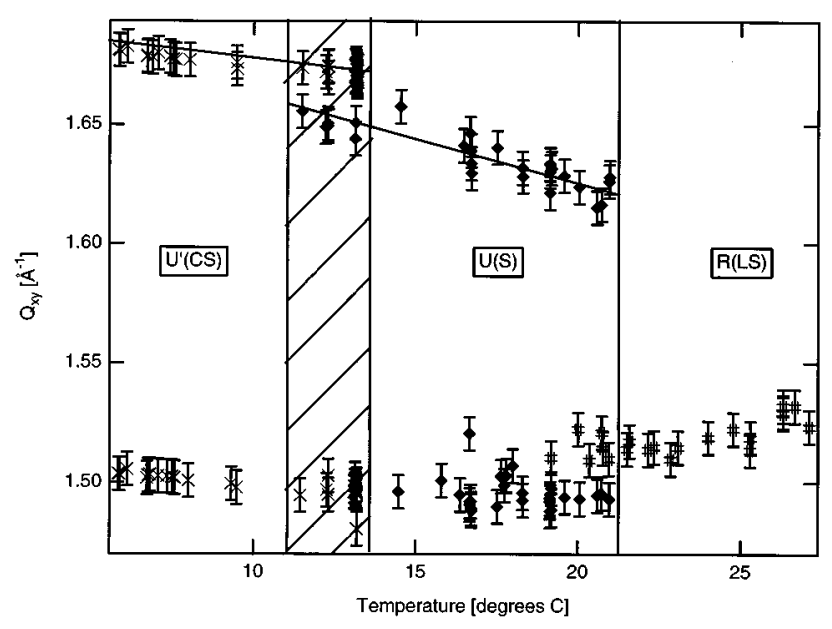

FIG. 2. Peak positions vs temperature in the vicinity of the $U^{\prime}(C S) /$ $U(S) / R(L S)$ phase transitions at $\pi \sim 15$ dynes/cm. The symbols represent: $\times-U^{\prime}(C S),-U(S)$, and \#-R(LS). 

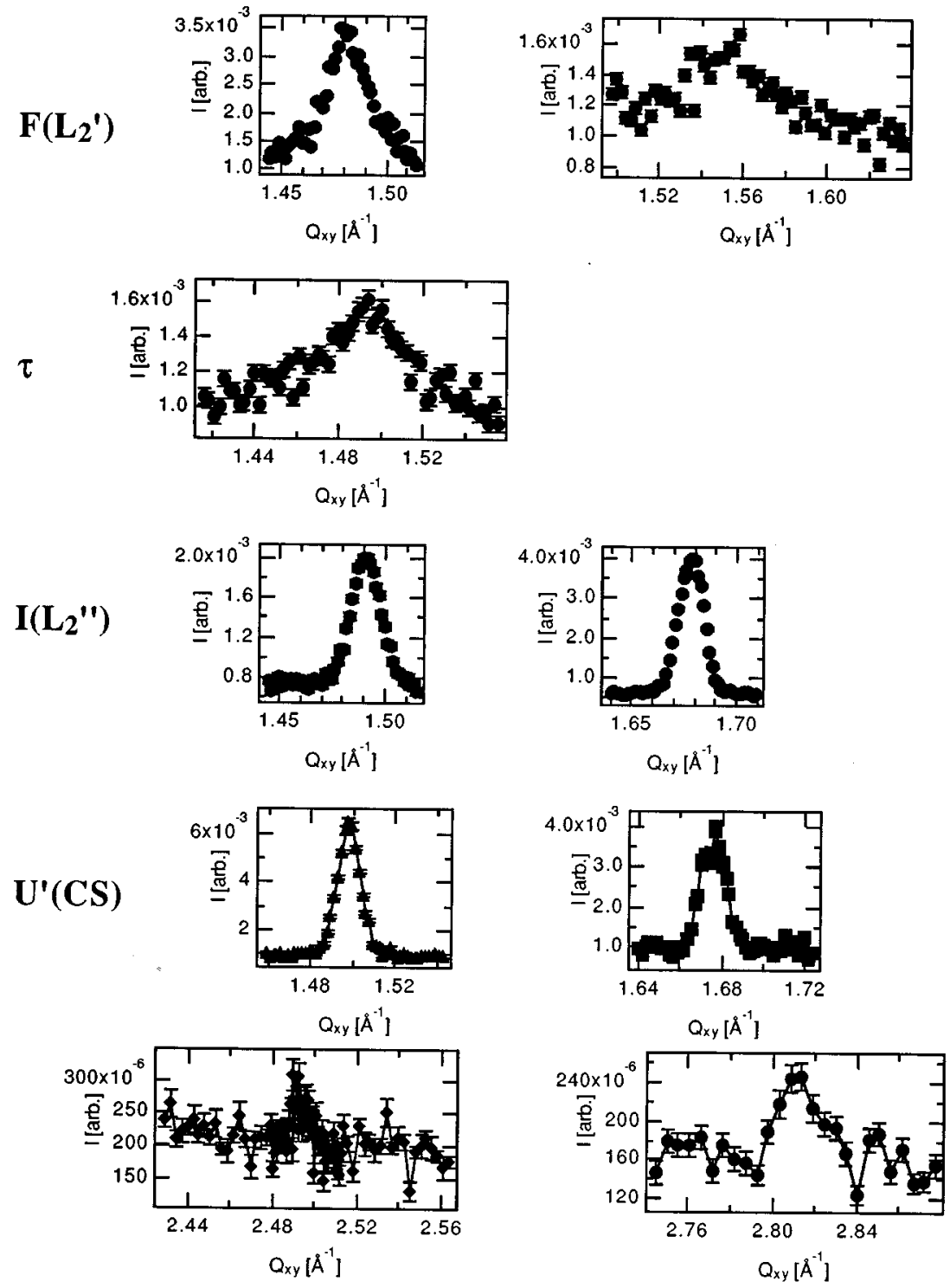

FIG. 3. Diffraction peaks in the $I\left(L_{2}^{\prime \prime}\right), F\left(L_{2}^{\prime}\right), \tau$, and $U^{\prime}(C S)$ phases. In the $I\left(L_{2}^{\prime \prime}\right)$ phase, the peak at $Q_{x y} \sim 1.49 \AA^{-1}$ is out of plane. In the $F\left(L_{2}^{\prime}\right)$ phase, the peak at $Q_{x y} \sim 1.55 \AA^{-1}$ is the higher $Q_{z}$ peak. Both first and second order diffraction peaks are shown for the $U^{\prime}(C S)$ phase.

which the unit cell is hexagonal. The temperature dependence of the in-plane momentum transfer, corresponding to Bragg peaks associated with these three phases at $\pi \sim 15$ dynes/cm, is illustrated in Fig. 2.

It should be noted that over a small range of temperatures, peaks characteristic of both the $U^{\prime}(C S)$ and the $U(S)$ phases were observed simultaneously. The possibility of identifying this overlapping region as an additional phase of monoclinic symmetry is discounted by the fact that the unit cell area would be $17.6 \AA^{2}$, much smaller than the $18.9 \AA^{2}$ seen in bulk alkanes. If the peak at $Q_{x y}=1.676 \AA^{-1}$ is identified as the $(1,0)$ peak and the peak at $Q_{x y}=1.498 \AA^{-1}$ as the $(0,1)$ peak, then the observation of the second order $(1,1)$ $\left(Q_{x y}=2.809 \AA^{-1}\right)$ and $(-1,2)\left(Q_{x y}=2.492 \AA^{-1}\right)$ peaks in the $U^{\prime}(C S)$ phase indicates a relatively high degree of order. See Fig. 3.

At lower pressures, the observed tilted phases labeled
$I\left(L_{2}^{\prime \prime}\right)$ and $F\left(L_{2}^{\prime}\right)$ possess orthorhombic structures that differ primarily in the direction of the tilt. $I\left(L_{2}^{\prime \prime}\right)$ is tilted toward the nearest neighbor and $F\left(L_{2}^{\prime}\right)$ is tilted toward the next nearest neighbor. For $\pi<0.5$ dynes $/ \mathrm{cm}$, the momentum transfer, corresponding to Bragg peaks of the $I\left(L_{2}^{\prime \prime}\right)$ phase are $\left(Q_{x y}, Q_{z}\right)=\left(1.47 \pm 0.02 \AA^{-1}, 0.28 \pm 0.03 \AA^{-1}\right)$ and $(1.68$ $\left.\pm 0.02 \AA^{-1}, 0\right)$ independent of temperature. This is identified as the $I\left(L_{2}^{\prime \prime}\right)$ phase because its symmetry and x-ray area are similar to those of the $I\left(L_{2}^{\prime \prime}\right)$ phase in the fatty acids. ${ }^{8,23,24,40}$ The alkane chains are tilted toward the nearest neighbor position, as can be deduced ${ }^{21,41}$ from the peak positions, and the diffraction peaks are resolution limited. As indicated by the tilt data shown in Fig. 4, at slightly higher pressures, the peak positions have only a slight temperature and pressure dependence.

This phase is sensitive to radiation exposure and after 


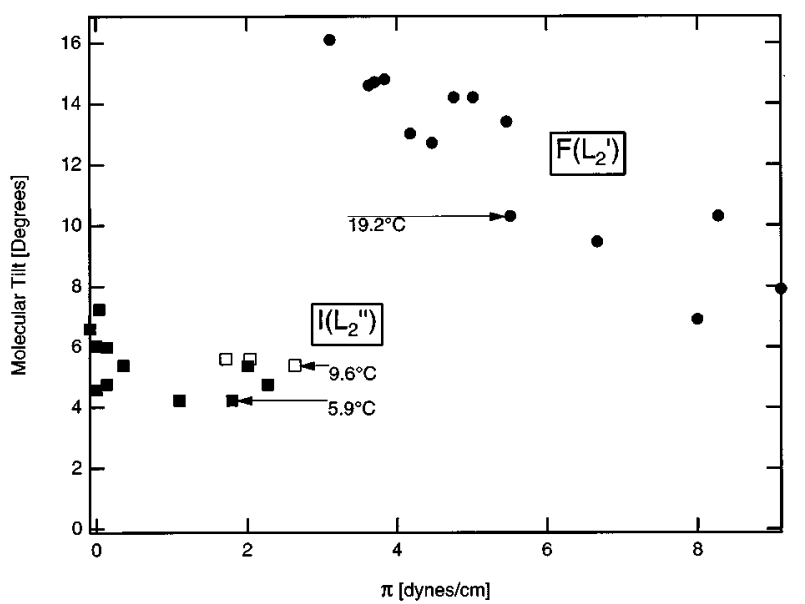

FIG. 4. Typical pressure dependence of the molecular tilt in the $I\left(L_{2}^{\prime \prime}\right)$ and $F\left(L_{2}^{\prime}\right)$ phases.

exposure at one fixed position at a flux rate of $10^{8}$ photons/s- $\mathrm{mm}^{2}$ for approximately one hour the molecules become untilted. To reduce the x-ray dose that any film received, the radiation was limited by blocking the beam during the periods when the film was relaxing. The effect of radiation exposure on phase boundary positions was studied by comparing isotherms for which the x-ray beam illuminated the sample for variable periods with others for which the flux impinging on the sample was constant throughout the isotherm. Whenever the exposure exceeded approximately one hour at this exposure rate, isotherm data was not reproducible.

Upon warming the film at low pressure $(\pi<2.5$ dynes/ $\mathrm{cm})$, there is a transition to a phase tilted toward next-nearest neighbor [the $F\left(L_{2}^{\prime}\right)$ phase] at $\sim 14{ }^{\circ} \mathrm{C}$. As shown by the data in Fig. 5, both of the diffraction peaks of this phase are out of the plane of the surface with $Q_{z}$ values of approximately 0.4 and $0.2 \AA^{[1]}$. The pressure dependence of the mean molecular tilt extracted from the position of the diffraction peaks ${ }^{25,40,41}$ is shown in Fig. 4. As can be seen from Fig. 4, the pressure dependence of the tilt in the $F\left(L_{2}^{\prime}\right)$ phase is considerably stronger than in the $I\left(L_{2}^{\prime \prime}\right)$ phase, for which the tilt is essentially independent of pressure. Radiation damage was also observed for the $F\left(L_{2}^{\prime}\right)$ phase, in that the peaks at the higher $Q_{z}$ value fade with increasing dose [similar to the $I\left(L_{2}^{\prime \prime}\right)$ phase]. However, the peak at lower $Q_{z}$ was essentially unchanged.

Others have concluded that the $F\left(L_{2}^{\prime}\right)$ phase is hexatic. ${ }^{6}$ Although the broad lineshapes for the $F\left(L_{2}^{\prime}\right)$ data shown in Fig. 3 support this identification, the data taken in this study are not sufficient to independently identify this as a hexatic phase. Nevertheless, the results are consistent with it being hexatic. Below, interpretation of BAM images, taken of macroscopic $I\left(L_{2}^{\prime \prime}\right)$ domains formed on cooling from the $F\left(L_{2}^{\prime}\right)$ phase, will be based upon this idea.

As the temperature is raised above $22^{\circ} \mathrm{C}$, (for $\pi<9$ dynes $/ \mathrm{cm}$ ) the two peaks shift their in-plane positions, $Q_{x y}$, until they merge (see Fig. 5). The combination of a single

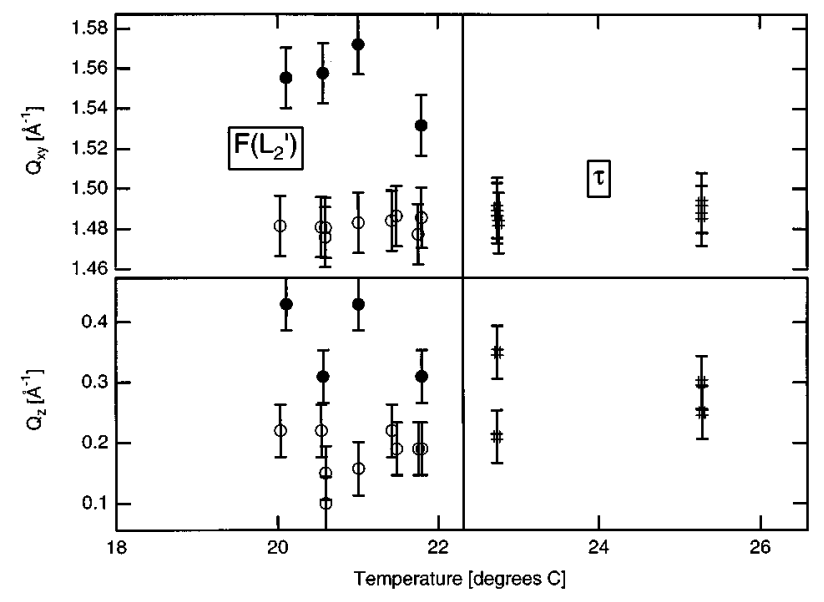

FIG. 5. The in-plane and out-of-plane momentum transfer for $\pi$ between 4 and 5 dynes/cm as a function of temperature. $F\left(L_{2}^{\prime}\right)$ is indicated by $\bigcirc$ (lower peak) and $\bigcirc$ (upper peak) and $\tau$ by \#.

peak along $Q_{x y}$ and the maximum intensity at $Q_{z} \neq 0$ implies a phase transition from the $F\left(L_{2}^{\prime}\right)$ phase to a hexagonal, Rotator IV-like phase ${ }^{42}$ in which the molecular chains are tilted with respect to the surface normal. For discussion, we refer to this as the $\tau$ phase.

One advantage of taking diffraction data simultaneously with a relaxation isotherm is that the system can be represented in terms of the microscopic variables $\pi$ and the x-ray area, $A_{X}$, (as opposed to the less reliable ratio between the macroscopic trough area, $A_{T}$, and the number of deposited molecules). Figure 6 provides such a diagram. In Fig. 7, the tilt and surface pressure are shown as a function of $A_{X}$ for all of the data in the $I\left(L_{2}^{\prime \prime}\right)$ and $F\left(L_{2}^{\prime}\right)$ phases indicated in Fig. 6. Viewed in this way, one can see that within each phase the molecular tilt is primarily a function of x-ray area, regardless of temperature.

\section{BREWSTER ANGLE MICROSCOPY}

In many cases, the identification of phase transitions and the distinction between similar phases is facilitated by supplemental optical microscope techniques. ${ }^{6,43-53}$ In the present context, BAM observations have proven useful in providing additional information on the $I\left(L_{2}^{\prime \prime}\right)$ to $F\left(L_{2}^{\prime}\right)$ transition as well as on the texture of the film. For example, Fig. 8 contains images that show compression of a film deposited in the $I\left(L_{2}^{\prime \prime}\right)$ phase at $T=5^{\circ} \mathrm{C}$ and low density. The monolayer is clearly inhomogeneous and it is clear how compression squeezes out the dark areas of low density.

Figure 9 illustrates another interesting phenomenon. The image in Fig. 9(a) corresponds to an inhomogeneous film, like that in Fig. 8, which was deposited at low temperature in the $I\left(L_{2}^{\prime \prime}\right)$ phase. It appears isotropic, except for dark regions of a gaseous phase. On the other hand, if the film is deposited in the higher temperature $F\left(L_{2}^{\prime}\right)$ phase and then cooled into the $I\left(L_{2}^{\prime \prime}\right)$ phase, the texture, shown in Fig. 9(b), is observed. In both cases, diffraction measurements revealed identical tilted $I\left(L_{2}^{\prime \prime}\right)$ structures. 


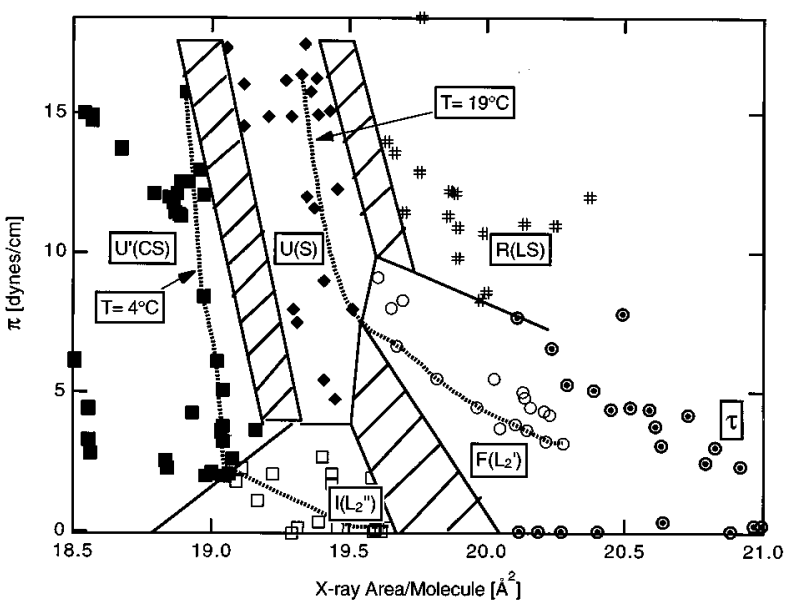

FIG. 6. The phase diagram of methyl eicosanoate in terms of the full, relaxed surface pressure, $\pi$ and the x-ray determined area per molecule $A_{X}$. The points where the different phases were observed are shown as: $\square-$ $I\left(L_{2}^{\prime \prime}\right), \bigcirc-F\left(L_{2}^{\prime}\right), \odot-\tau, \boldsymbol{\square}-U^{\prime}(C S),-U(S), \#-R(L S)$. The solid lines represent phase boundaries. In the case of the $U^{\prime}(C S)-U(S)-R(L S)$ transitions, the cross-hatched areas represent observed limits of coexistence due to supercooling or superheating. Typical isotherms are shown by dashed lines.

The differences are suspected to be due to the manner in which the monolayer is formed. For example, on deposition at low temperature and low density, the $I\left(L_{2}^{\prime \prime}\right)$ domains form through a homogeneous nucleation and growth process that results in multiple microscopic two-dimensional crystals. In contrast, the higher temperature $F\left(L_{2}^{\prime}\right)$ phase is thought to be a more fluid hexatic mesophase. ${ }^{8}$ It can be argued that larger, macroscopic domains can grow by a grain coarsening process in the fluid phase. The $I\left(L_{2}^{\prime \prime}\right)$ domains that form on slow cooling from the $F\left(L_{2}^{\prime}\right)$ should be larger. This is what is observed.

The changes in texture observed on warming a monolayer deposited in the $I\left(L_{2}^{\prime \prime}\right)$ phase at low temperature into the $F\left(L_{2}^{\prime}\right)$ phase is shown in Fig. 10. There is some faint but

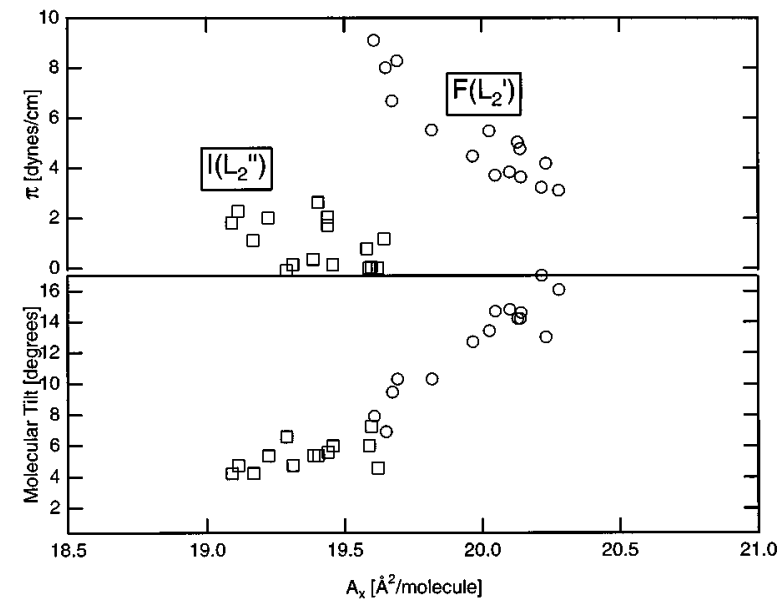

FIG. 7. The molecular tilt and surface pressure for the $F\left(L_{2}^{\prime}\right)$ and $I\left(L_{2}^{\prime \prime}\right)$ phases as a function of the x-ray unit cell area, $A_{X}$. observable coarsening of the film homogeneity between the images at $12.5^{\circ} \mathrm{C}$ and $14.5^{\circ} \mathrm{C}$ that corresponds to the transition from the $I\left(L_{2}^{\prime \prime}\right)$ to the $F\left(L_{2}^{\prime}\right)$ phase. This is followed by a more dramatic textural change to the image at $23.5^{\circ} \mathrm{C}$ that corresponds to the $\tau$ phase. The images of the $\tau$ phase show larger domains than those of the $F\left(L_{2}^{\prime}\right)$ phase, along with various shades of gray that indicate that this phase is also tilted. It should be noted that the textures of the untilted phases are much more uniform than that of the $\tau$ phase.

\section{ISOTHERMS}

In contrast to the fatty acid system studied earlier, ${ }^{24}$ the isotherms of the methyl ester show none of the irreproducible features that were present in relaxation isotherms of the acids. The temporal sequence for a typical isotherm is shown in Fig. 11. The trend of short relaxations at large areas and longer relaxations at smaller areas, visible here, was observed throughout the study. This trend has been explained previously. ${ }^{24}$ At large area, the film is made up of islands of molecules in coexistence with a gaseous phase. As the area is reduced and the islands are squeezed together, relaxation effects are dominated by local shape changes necessitated by the points where islands come into contact. These are necessarily more rapid than macroscopic, nonlocal grain boundary relaxations that become required as the molecular density saturates. Significant compression beyond saturation requires some removal of molecules from the surface. In contrast to the case of fatty acids, for which the compression past saturation leads to monolayer collapse and $\pi$ decaying to zero, it is shown in Fig. 12 that, for the present system, the $\pi$ of the saturated monolayer appears to be stable. This probably indicates thermodynamic equilibrium with either a multilayer phase or some other three dimensional phase.

This result is consistent with a measurement, conducted as part of this study, of the equilibrium spreading pressure, $\pi_{\text {esp }}$, (the surface pressure when a crystal of bulk is placed in contact with the water surface) of 14 dynes $/ \mathrm{cm}$ at $30^{\circ} \mathrm{C}$. For fatty acids of comparable chain lengths, $\pi_{\text {esp }}$ was immeasurably small. Also consistent with this is the fact that, unlike in the fatty acid films, 3D crystallites are not observed after the pressure saturates.

\section{INTERPRETATION}

The most relevant earlier study of an ester monolayer is that of Stenhagen, ${ }^{26}$ in which a phase diagram was derived from only isotherms. Lundquist ${ }^{27}$ later extended this research using isotherms to map out the phase diagram of the ethyl esters. Isotherm measurements were supplemented by measurements of surface pressure vs temperature at fixed area. With this data, the Clasius-Claperyon relation was invoked to calculate the enthalpy accompanying the observed transitions. The phase diagram that has been determined in this study shows a similar topology to the diagram presented in the work of Lundquist, ${ }^{27}$ which only differs from diagrams presented by Bibo, ${ }^{54}$ and Stenhagen ${ }^{26}$ in some regions of low surface pressure. Some of these differences are not particularly surprising since without some sort microscopic probe 

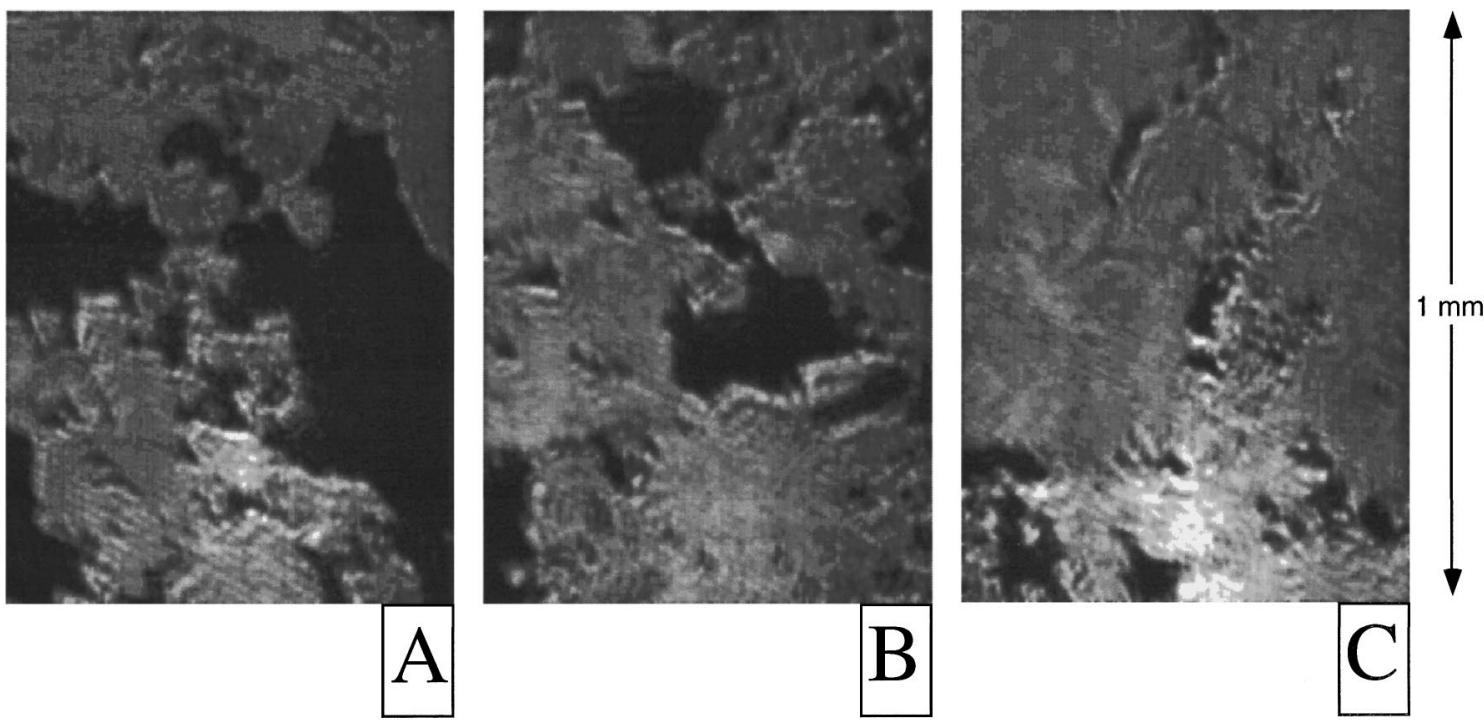

FIG. 8. BAM pictures showing compression of the $I\left(L_{2}^{\prime \prime}\right)$ phase at $T=4.97{ }^{\circ} \mathrm{C}$ and low $\pi$. Note that the free area is squeezed out as the film is compressed [from (A) to figure (C)].

the relation between tilt and near neighbor direction must be indirect. Using only isotherm measurements, Lundquist ascribed the same symmetry to the phases as has been determined here, although with no reason given for that particular identification. Bibo performed a miscibility study of ethyl eicosanoate and docosanoic acid and concluded that the high temperature, low pressure phase is tilted toward nearest neighbor. Finally, Stenhagen concluded, on the basis of isotherm measurements, that the low temperature, low pressure phase is $U^{\prime}(C S)$ and the high temperature, low pressure phase is tilted toward nearest neighbor. It should be noted that this investigation was conducted on the methyl esters,
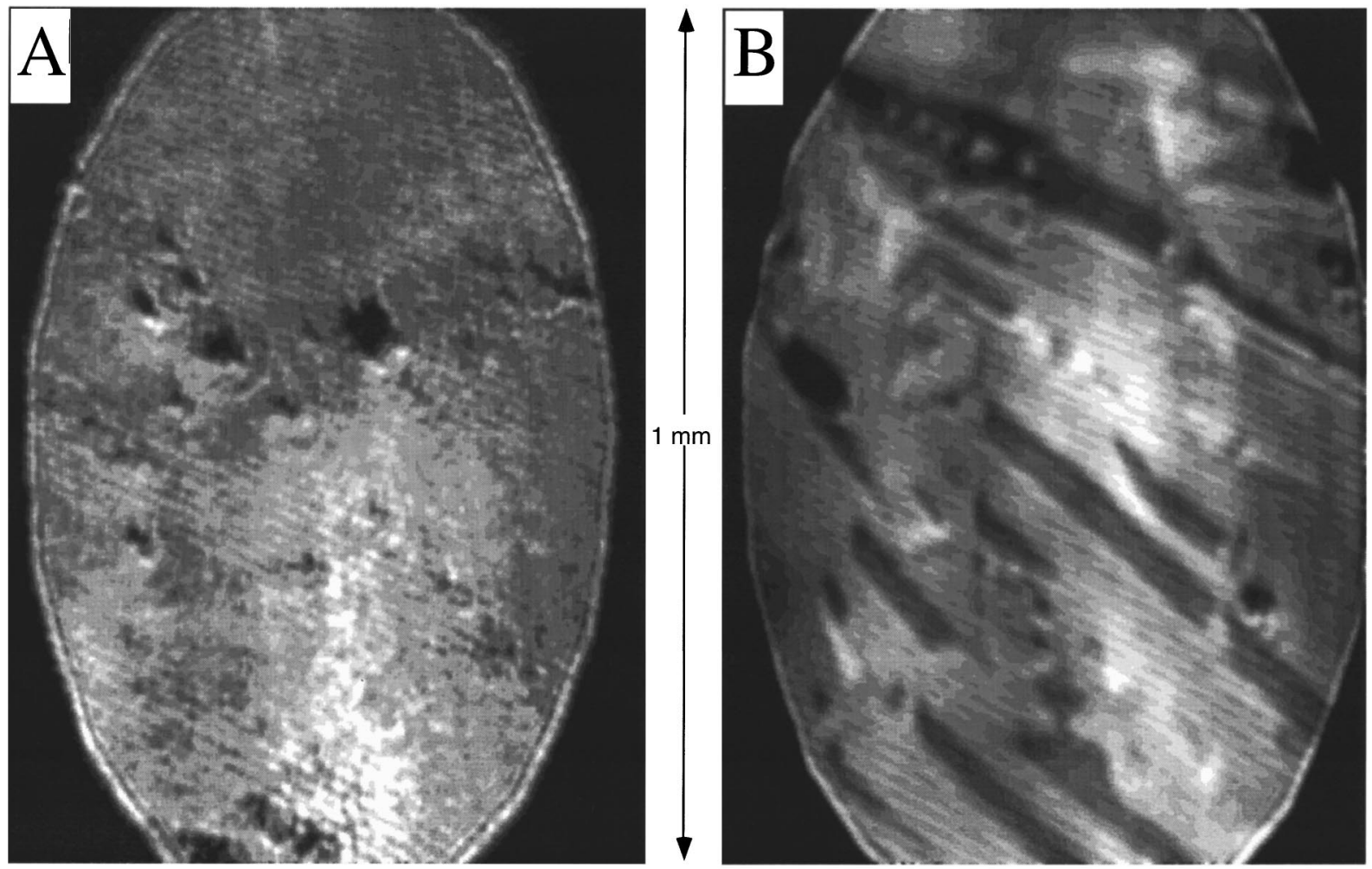

FIG. 9. BAM pictures showing the structure of the $I\left(L_{2}^{\prime \prime}\right)$ phase produced by spreading (A) vs cooling spread film (b). The film on the left is spread at $5{ }^{\circ} \mathrm{C}$, the film on the right (with the camera iris visible) was spread at $25^{\circ} \mathrm{C}$ and cooled to $5{ }^{\circ} \mathrm{C}$. Both images have been scaled to correct for the geometry of the microscope. 

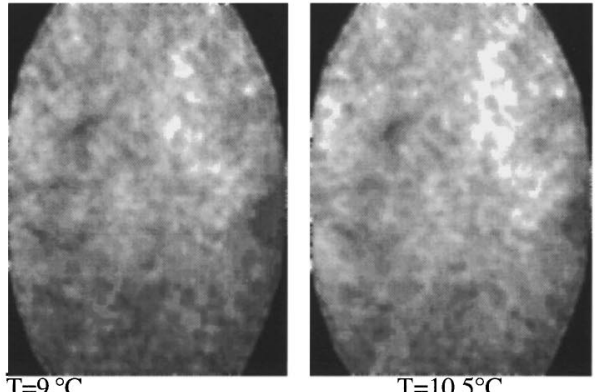

$\mathrm{T}=10.5^{\circ} \mathrm{C}$
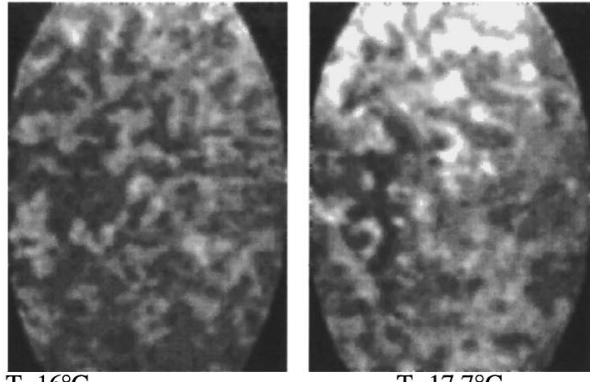

$\mathrm{T}=17.7^{\circ} \mathrm{C}$

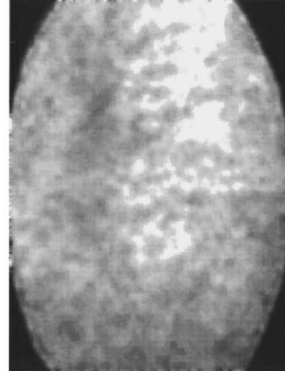

$\mathrm{T}=12.5^{\circ} \mathrm{C}$

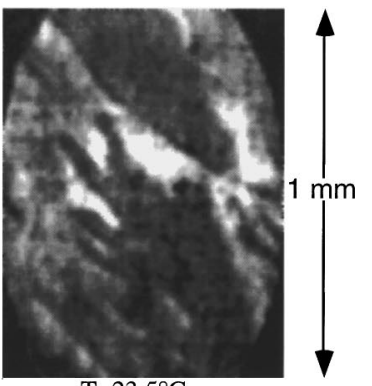

$\mathrm{T}=23.5^{\circ} \mathrm{C}$

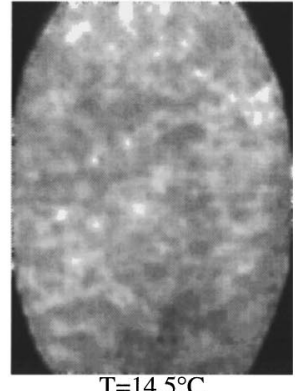

$\mathrm{T}=14.5^{\circ} \mathrm{C}$

FIG. 10. BAM images showing textural changes on warming a film, initially deposited in the $I\left(L_{2}^{\prime \prime}\right)$ phase, into the $F\left(L_{2}^{\prime}\right)$ phase.

while Lundquist and Bibo studied the ethyl ester system. The difference between the results described here and the work of Bibo perhaps may be due to the difference between the methyl ester and ethyl ester system. However, this will only be resolved when structural measurements for the ethyl ester system are available.

The untilted phases in this system, as observed in both the BAM and x-ray measurements, are similar to those seen in films of other materials. Because these three phases have been observed in many films including fatty acid and alcohol
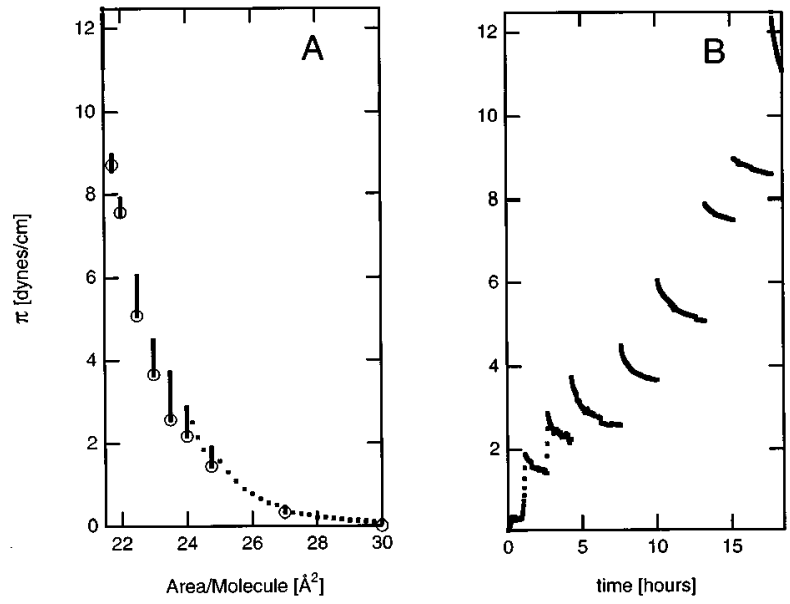

FIG. 11. A typical relaxation isotherm of methyl eicosanoate at $T=21^{\circ} \mathrm{C}$. (A) shows the pressure as a function of area, with relaxations in pressure visible as lines at constant area. The relaxed points are shown by the $\bigcirc$ symbols. (B) shows the same data as a function of time. The relaxation of the pressure is clearly visible here. systems at high density, ${ }^{16,38,39}$ it is widely thought ${ }^{38}$ that the structure of these phases is due primarily to chain-chain interactions. Additional weight is given to this hypothesis by the similarity of bulk alkane chain packing ${ }^{42}$ to the structures observed in these films. Nevertheless, recent studies of mixed acid/alcohol monolayers by Fischer et al. show dramatic variations with the polar head group. ${ }^{53}$ All of these transitions have been described within the framework of a phenomenological Landau theory. ${ }^{11}$
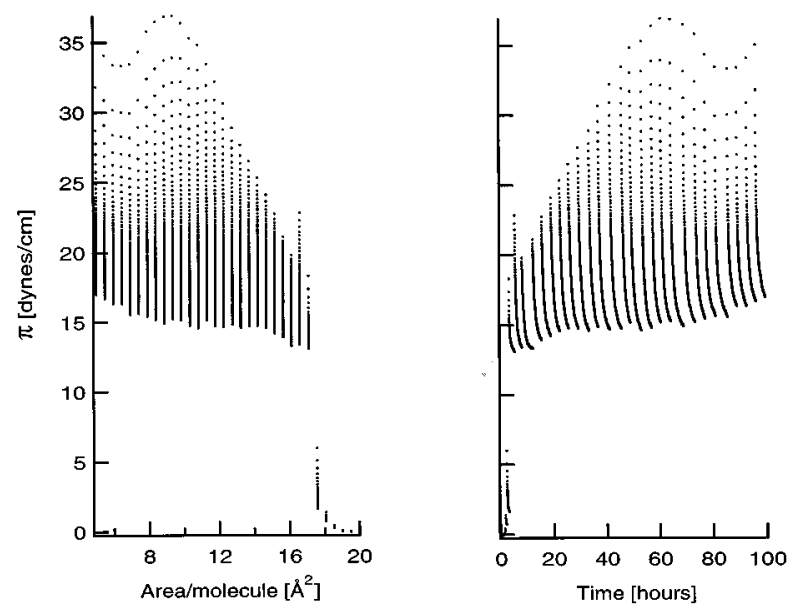

FIG. 12. Demonstration of how the pressure relaxes to the same value after each compression for $\pi \approx 15$ dynes/cm. 
A new phase, the $\tau$ phase, that was observed in this study is illustrated by the data in Fig. 5. Two peaks are observed with in-plane momentum transfers that merge with increasing temperature. The film remains tilted since both peaks are out of the plane. On the basis of these measurements, it is believed that the new phase has a Rotator IV-like structure.

\section{CONCLUSION}

The structure and phases of a relaxed ${ }^{17,24}$ Langmuir monolayer (LM) of methyl eicosanoate was studied in the temperature range of 5 to $27^{\circ} \mathrm{C}$ using BAM and grazing incidence $\mathrm{x}$-ray scattering. Relaxation isotherms taken on this system were reproducible and reflected structural features of the film directly observed by x-ray scattering. Six phases were identified (see Fig. 1). The three untilted phases, present at high pressure, are similar to those seen at high pressure in other saturated alkane system. ${ }^{8,11}$ At low pressure, there are three phases: the $I\left(L_{2}^{\prime \prime}\right)$; the $F\left(L_{2}^{\prime}\right)$, and the $\tau$. The $I\left(L_{2}^{\prime \prime}\right)$ phase, present at low temperature, is crystalline with the molecules tilted toward nearest neighbor. The $F\left(L_{2}^{\prime}\right)$ phase, present between $13{ }^{\circ} \mathrm{C}$ and $22^{\circ} \mathrm{C}$, is thought to be hexatic ${ }^{6}$ with tilt toward the next nearest neighbor. Finally, the $\tau$ phase, present above $22^{\circ} \mathrm{C}$, has a similar structure to the $F\left(L_{2}^{\prime}\right)$ phase, with the exception that it has a rotator-IV-like structure that averages out the in-plane distortions, resulting in a single $Q_{x y}$ peak.

These measurements have resolved an ongoing controversy ${ }^{26,27,54}$ as to the microscopic structure of the various phases within this system.

\section{ACKNOWLEDGMENTS}

The research described here was supported by Grant Nos. NSF-DMR-91-13782, NSF-DMR-94-00396, and NSFDMR-95-23440. Some of the experiments were carried out on the Harvard/BNL liquid surface reflectometer on beam line X22B at the National Synchrotron Light Source, Brookhaven National Laboratory. This facility is supported by Grant No. DE-AC02-76CH00016.

\footnotetext{
${ }^{1}$ N. W. Ashcroft and N. D. Mermin, Solid State Physics (Holt, Rinehart, and Winston, New York, 1976).

${ }^{2}$ P. deGennes, Scaling Concepts in Polymer Physics (Cornell University Press, Ithaca and London, 1979).

${ }^{3}$ P. deGennes and J. Prost, The Physics of Liquid Crystals (Oxford University Press, New York, 1994).

${ }^{4}$ A. Sali, E. Shakhnovich, and M. Karplus, Nature 369, 248 (1994).

${ }^{5}$ M. K. Durbin, A. Malik, R. Ghaskadvi, M. C. Shih, P. Zschack, and P. Dutta, J. Phys. Chem. 98, 1753 (1994).

${ }^{6}$ B. Fischer, M. W. Tsao, J. Ruiz-Garcia, T. M. Fischer, D. K. Schwartz, and C. M. Knobler, J. Phys. Chem. 98, 7430 (1994).

${ }^{7}$ G. A. Overbeck and D. Mobius, J. Phys. Chem. 97, 7999 (1993).
}

${ }^{8}$ V. M. Kaganer, I. R. Peterson, R. M. Kenn, M. C. Shih, M. Durbin, and P. Dutta, J. Chem. Phys. 102, 9412 (1995).

${ }^{9}$ I. Langmuir, J. Am. Chem. Soc. 39, 1848 (1917).

${ }^{10}$ D. R. Nelson and B. I. Halperin, Phys. Rev. B 19, 2457 (1979).

${ }^{11}$ V. M. Kaganer and E. B. Loginov, Phys. Rev. Lett. 71, 2599 (1993).

${ }^{12}$ M. Losche and H. Möhwald, Rev. Sci. Instr. 55, 1968 (1984).

${ }^{13}$ S. Henon and J. Meunier, Rev. Sci. Instr. 62, 936 (1991).

${ }^{14}$ B. Moore, C. M. Knobler, D. Broseta, and F. Rondelez, J. Am. Chem. Soc., Faraday Trans. 2, 1753 (1986).

${ }^{15}$ K. Kjaer, J. Als-Nielsen, C. A. Helm, L. A. Laxhuber, and H. Möhwald, Phys. Rev. Lett. 58, 2224 (1987).

${ }^{16}$ B. Lin, M. C. Shih, T. M. Bohanon, G. E. Ice, and P. Dutta, Phys. Rev. Lett. 65, 191 (1990).

${ }^{17}$ M. L. Schlossman, D. K. Schwartz, P. S. Pershan, E. H. Kawamoto, G. J. Kellogg, and S. Lee, Phys. Rev. Lett. 66, 1599 (1991).

${ }^{18}$ B. Berge, Phys. Rev. Lett. 73, 1652 (1994).

${ }^{19}$ J. P. Rieu, J. F. Legrand, A. Renault, B. Berge, B. M. Ocko, X. Z. Wu, and M. Deutsch, J. Phys. II 5, 607 (1995).

${ }^{20}$ X. Qiu, J. Ruiz-Garica, and C. M. Knobler, Mater. Res. Soc. Symp. Proc. 237, 263 (1992)

${ }^{21}$ J. Als-Nielsen and H. Möwald, in Handbook of Synchrotron Radiation, Vol. 4, edited by S. Ebashi, E. Rubenstein, and M. Koch (North Holland, Amsterdam, 1991), p. 1.

${ }^{22}$ D. Jacquemain, S. G. Wolf, F. Leveiller, M. Deutsch, K. Kjaer, J. AlsNielsen, M. Lahav, and L. Leiserowitz, Angew. Chem. Int. Ed. Engl. 31, 130 (1992).

${ }^{23}$ P. Dutta, in Phase Transitions in Surface Films, edited by H. Taub, G. Torzo, H. Lauter, and S. Fain, (Plenum, New York, 1991),

${ }^{24}$ G. M. Bommarito, W. J. Foster, P. S. Pershan, and M. L. Schlossman, J. Chem. Phys. (to be published).

${ }^{25}$ D. K. Schwartz, M. L. Schlossman, and P. S. Pershan, J. Chem. Phys. 96, 2356 (1991)

${ }^{26}$ E. Stenhagen, in Determination of Organic Structures by Physical Methods, Vol. 1, edited by E. A. Braude and F. C. Nachod (Academic, New York, 1955), p. 325.

${ }^{27}$ M. Lundquist, Chem. Scr. 1, 197 (1971).

${ }^{28}$ K. S. Birdi, Lipid and Biopolymer Monolayers at Liquid Interfaces (Plenum, New York, 1989).

${ }^{29}$ G. L. Gaines, Insoluble Monolayers at Liquid-Gas Interfaces, Interscience Monographs on Physical Chemistry (Wiley, New York, 1966).

${ }^{30}$ C. M. Knobler, in Advances in Chemical Physics, edited by S. Rice and I. Prigogine (Wiley, New York, 1990), Vol. 77, p. 397.

${ }^{31}$ J. T. Buontempo and S. A. Rice, J. Chem. Phys. 98, 5835 (1993).

${ }^{32}$ T. Kato, Y. Hirobe, and M. Kato, Langmuir 7, 2208 (1991).

${ }^{33}$ R. E. Heikkila, C. N. Kwong, and D. G. Cornwell, J. Lipid Res. 11, 190 (1970).

${ }^{34}$ E. Pezron, P. M. Claesson, J. M. Berg, and Vollhardt, J. Coll. Interface Sci. 138, 245 (1990).

${ }^{35}$ D. K. Schwartz, Thesis, Harvard University, 1991.

${ }^{36}$ P. S. Pershan, Structure of Liquid Crystal Phases, World Scientific Lecture Notes in Physics (World Scientific, Teaneck, New Jersey, 1988).

${ }^{37}$ S. Stallberg-Stenhagen and E. Stenhagen, Nature 156, 239 (1945).

${ }^{38}$ S. W. Barton, B. N. Thomas, E. B. Flom, S. A. Rice, B. Lin, J. B. Peng, J. B. Ketterson, and P. Dutta, J. Chem. Phys. 89, 2257 (1988).

${ }^{39}$ M. C. Shih, T. M. Bohanon, J. M. Mikrut, P. Zschack, and P. Dutta, J. Chem. Phys. 97, 4485 (1992).

${ }^{40}$ K. Kjaer, J. Als-Nielsen, C. A. Helm, P. Tippman-Krayer, and H. Möhwald, J. Phys. Chem. 93, 3200 (1989).

${ }^{41}$ M. L. Schlossman and P. S. Pershan, in Light Scattering By Liquid Surfaces and Complementary Techniques, edited by D. Langevin (Marcel Dekker, New York, 1990), p. 365.

${ }^{42}$ E. B. Sirota, J. H. E. King, D. M. Singer, and H. H. Shao, J. Chem. Phys. 98, 5809 (1993).

${ }^{43}$ J.-M. Flesselles, M. O. Magnasco, and A. Libchaber, Phys. Rev. Lett. 67, 2489 (1991).

${ }^{44}$ L. Bourdieu, P. Silberzan, and D. Chatenay, Phys. Rev. Lett. 67, 2029 (1991)

${ }^{45}$ K. Miyano and K. Tamada, Langmuir 8, 160 (1992).

${ }^{46}$ D. K. Schwartz and C. M. Knobler, J. Phys. Chem. 97, 8849 (1993).

${ }^{47}$ S. Hénon and J. Meunier, J. Chem. Phys. 98, 9148 (1993).

${ }^{48}$ J. Ruiz-Garcia, X. Oiu, M.-W. Tsao, G. Marshall, C. M. Knobler, G. A. Overbeck, and D. Mobius, J. Phys. Chem. 97, 6955 (1993). 
${ }^{49}$ S. Riviere, S. Henon, J. Meunier, D. K. Schwartz, M.-W. Tsao, and C. M. Knobler, J. Chem. Phys. 101, 10045 (1994).

${ }^{50}$ G. Brezesinski, E. Scalas, B. Struth, H. Möhwald, F. Bringezu, U. Gehlert, G. Weidemann, and D. Vollhardt, J. Phys. Chem. 99, 8758 (1994).

${ }^{51}$ U. Gehlert, S. Siegel, and D. Vollhard, Polym. Sci. 93, 247 (1993).
${ }^{52}$ S. J. Stranick, P. S. Weiss, A. N. Parikh, and D. L. Allara, J. Vac. Sci. Tech. 11, 739 (1993).

${ }^{53}$ B. Fischer, E. Teer, and C. M. Knobler, J. Chem. Phys. 103, 2365 (1995).

${ }^{54}$ A. M. Bibo, C. M. Knobler, and I. R. Peterson, J. Phys. Chem. 95, 5591 (1991). 